\title{
Combining process-based and correlative models improves predictions of climate change effects on Schistosoma mansoni transmission in eastern Africa
}

\author{
Anna-Sofie Stensgaard, ${ }^{1}$ Mark Booth, ${ }^{2}$ Grigory Nikulin, ${ }^{3}$ Nicky McCreesh ${ }^{4}$ \\ ${ }^{1}$ Center for Macroecology, Evolution and Climate, the Natural History Museum of Denmark, \\ University of Copenhagen, Copenhagen, Denmark; ${ }^{2}$ School of Medicine, Pharmacy and \\ Health, Durham University, Durham, UK; ${ }^{3}$ Rossby Centre, Swedish Meteorological and \\ Hydrological Institute, Norrköping, Sweden; ${ }^{4}$ Department of Infectious Disease \\ Epidemiology, London School of Hygiene and Tropical Medicine, London, UK
}

\begin{abstract}
Currently, two broad types of approach for predicting the impact of climate change on vector-borne diseases can be distinguished: i) empirical-statistical (correlative) approaches that use statistical models of relationships between vector and/or pathogen presence and environmental factors; and ii) process-based (mechanistic) approaches that seek to simulate detailed biological or epidemiological processes that explicitly describe system behavior. Both have advantages and disadvantages, but it is generally acknowledged that both approaches have value in assessing the response of species in general to climate
\end{abstract}

Correspondence: Anna-Sofie Stensgaard, Center for Macroecology, Evolution and Climate, the Natural History Museum of Denmark, University of Copenhagen, Universitetsparken 15, 2100 Copenhagen, Denmark.

Tel: +45.26.297650.

E-mail: asstensgaard@snm.ku.dk

Key words: Schistosomiasis; Climate change; Modelling; Biomphalaria; Eastern Africa.

Acknowledgements: ASS is thankful to the Danish National Research Foundation for its support of the Center for Macroecology, Evolution and Climate. NM, GN and MB received funding for the research leading to results of the dynamical model from the European Union's Seventh Framework Programme (FP7/2007-2013) under grant agreement no. 266327. The funders had no role in the design of the experiments; the collection, analysis, and interpretation of data; in the writing of the manuscript; or in the decision to submit the manuscript for publication.

Received for publication: 18 August 2015.

Revision received: 5 November 2015.

Accepted for publication: 11 November 2015.

(C) Copyright A-S. Stensgaard et al., 2016

Licensee PAGEPress, Italy

Geospatial Health 2016; 11(s1):406

doi:10.4081/gh.2016.406

This article is distributed under the terms of the Creative Commons Attribution Noncommercial License (CC BY-NC 4.0) which permits any noncommercial use, distribution, and reproduction in any medium, provided the original author(s) and source are credited. change. Here, we combine a previously developed dynamic, agentbased model of the temperature-sensitive stages of the Schistosoma mansoni and intermediate host snail lifecycles, with a statistical model of snail habitat suitability for eastern Africa. Baseline model output compared to empirical prevalence data suggest that the combined model performs better than a temperature-driven model alone, and highlights the importance of including snail habitat suitability when modeling schistosomiasis risk. There was general agreement among models in predicting changes in risk, with $24-36 \%$ of the eastern Africa region predicted to experience an increase in risk of up-to $20 \%$ as a result of increasing temperatures over the next 50 years. Vice versa the models predicted a general decrease in risk in $30-37 \%$ of the study area. The snail habitat suitability models also suggest that anthropogenically altered habitat play a vital role for the current distribution of the intermediate snail host, and hence we stress the importance of accounting for land use changes in models of future changes in schistosomiasis risk.

\section{Introduction}

Climate change is ongoing with average global surface temperatures projected to be 1.4 to $3.1^{\circ} \mathrm{C}$ for $2081-2100$ relative to $1986-2005$ given moderate climate change scenarios (IPCC, 2013). This warming will be accompanied by perturbations in the global hydrologic cycle and patterns of precipitation (IPCC, 2013). These changes are expected to impact the transmission potential of a number of vector-borne diseases and diseases with invertebrate intermediate hosts (Parham et al., 2015b), as transmission potential in any given location is partly dependent on abiotic factors affecting either free-living life stages and/or those which occur in the poikilothermic vector/intermediate host organisms such as snails and mosquitoes. Additionally, the geographical distribution and magnitude of disease are likely to be governed by a multitude of transmission-related non-climatic factors, including epidemiological, environmental, social, economic and demographic factors (Parham et al., 2015a).

Schistosomiasis, caused by species of the genus Schistosoma spp., will also inevitably be influenced by changing climate as both the schistosome parasite and its intermediate host snails are highly sensitive to changes in water temperature (Foster, 1964; Appleton, 1978; Pfluger, 1980). New areas may become suitable for schistosomiasis transmission, and currently endemic areas may experience changed incidence, which will impact on the feasibility of schistosomiasis con- 
trol and elimination goals in the medium to long-term. As such, predictions about changes in geographical distribution and transmission risk are imperative in order to identify appropriate mitigation, control and adaption strategies. However, only a few attempts have been made to predict changes in schistosomiasis transmission due to global warming, and results have been conflicting. While some models forecast an expansion into cooler areas and a potential for increased transmission (Martens et al., 1995; Zhou et al., 2008; McCreesh et al., 2015), others point to an overall reduction, or a geographical range shift as a consequence of warming (Martens et al., 1997; Stensgaard et al., 2013), highlighting that the relationship between temperature and disease risk is not a straightforward one (Mangal et al., 2008). Two broad types of approach for predicting the impact of climate change on schistosomiasis (and vector-borne diseases in general) can be distinguished: i) an empirical-statistical (correlative) approach that use statistical models of relationships between snail and/or parasite presence and environmental factors (Pedersen et al., 2014; Stensgaard et al., 2013); and ii) a process-based (mechanistic) approach based on experimentally obtained data on the functional, non-linear, relationship between parasite and temperature (e.g., McCreesh et al., 2015).

Both have advantages and disadvantages: geostatistical models of schistosomiasis risk, although often incorporating temperature, are limited by often imperfect empirical data and the complex, non-linear relationship between water temperature and infection risk (McCreesh and Booth, 2013), which mean they are unlikely to capture the full contribution of temperature. On the other hand, mathematical models that focus solely on the effect of temperature run the risk of over-simplification as the occurrence of schistosome parasites and intermediate host snails is not solely determined by temperature. Hence, the exclusion of other important (non-climatic) variables, particularly those relevant for the habitat suitability for the intermediate host snails (e.g., land cover type, soil properties) may lead to unrealistic predictions.

Here, we embrace both approaches, and combine a previously developed dynamic, temperature-driven model (agent-based) of the temperature-sensitive stages of the Schistosoma (S.) mansoni and intermediate host snail lifecycles (McCreesh et al., 2015), with an empirical-statistical model of snail habitat suitability, to improve predictions of climate change impacts for intestinal schistosomiasis risk in the eastern Africa region. This approach is novel in the context of climate changedisease modelling, and has the potential to greatly improve predictions of the impact of climate change on schistosomiasis and vector-borne diseases in general.

\section{Materials and Methods}

\section{Baseline (current conditions) models}

\section{Snail habitat suitability modelling}

The empirical-statistical models of species geographical distributions - often referred to collectively as species distribution models (SDMs), share a common generic approach (Hirzel et al., 2006). Known species' presence localities are used as the dependent variable and a series of environmental variables (e.g. temperature, precipitation and land use) across the study area, are used as predictor variables. The suitability of each unit in the study-area is defined as a function of these environmental variables, and can also be estimated under changed climatic conditions (Pearson and Dawson, 2003).

Several different algorithms have been applied for SDM (Elith et al., 2006). Here we use the MaxEnt approach proposed by Phillips et al. (Phillips et al., 2006), which has been shown to perform well compared to other predictive algorithms (Elith et al., 2006), and recently also applied to vector-borne diseases (Mwase et al., 2014; Signorini et al., 2014).

MaxEnt estimates species distribution by finding the maximum entropy (largest spread) in a dataset of species geographic presences in relation to a set of background environmental variables (Phillips et al., 2006). Complex relationships to the environmental data can be fitted (i.e. threshold and hinge features interactions), but since these relationships can be difficult to specify a priory, only linear, quadratic and product relationships were fitted for the snail models. The output from MaxEnt can be interpreted as an estimate of relative habitat suitability for the species being modelled, and varies from 0 (lowest) to 1 (highest).

The models were parametrised with Biomphalaria (B.) pfeifferi occurrence data compiled from two main sources: the Mandahl-Barth mollusc collection maintained at the Natural History Museum, University of Copenhagen, Denmark, and Brown's collection maintained at the Natural History Museum (London, UK). The data were supplemented with more recent field data collected during the 4 yearlong EU Framework project, CONTRAST (Utzinger et al., 2013). A more detailed description of the data is given in Stensgaard et al. (2013). For the eastern Africa region, a total of 392 geocoded data points were available for snail habitat suitability modelling.

A range of environmental predictor variables were selected based on their perceived biological relevance for intermediate host snail distri-

Table 1. Data sources and properties of the remotely sensed and other non-climatic environmental predictors used to model the snail habitat suitability for Biomphalaria pfeifferi in eastern Africa.

\begin{tabular}{|c|c|c|c|}
\hline Data type & Spatial resolution & Time period & Source \\
\hline Land cover & $300 \times 300 \mathrm{~m}$ & 2009 & GlobCover \\
\hline Soil moisture & $300 \times 300 \mathrm{~m}$ & 2006-2012 & ESA CCI \\
\hline NDVI (seasonal averages) & $1 \times 1 \mathrm{~km}$ & $2000-2012$ & MODIS/Terra \\
\hline Water bodies (lakes and wetlands) & $1 \times 1 \mathrm{~km}$ & 2005 & GLCN/FAO \\
\hline Dams (distance-grid) & $1 \times 1 \mathrm{~km}$ & 2005 & GLCN/FAO \\
\hline HII & $1 \times 1 \mathrm{~km}$ & $1995-2004$ & SEDAC \\
\hline Soil pH (topsoil) & $1 \times 1 \mathrm{~km}$ & - & ISRIC \\
\hline
\end{tabular}


butions (Table 1) and commonly used freshwater snail distribution models (Simoonga et al., 2009; Stensgaard et al., 2005, 2006). Temperature was not included as this is represented in the dynamical model (see below).

The measure of fit implemented by MaxEnt is the area under the curve (AUC) of a receiver operating characteristic (ROC) plot (ranging from $0.5=$ random to $1=$ perfect discrimination). The performance of the MaxEnt model was evaluated by a 10 -fold cross-validation procedure where data are divided into 10 mutually exclusive subsets; where 10-1 are used for model training, and 1 for model testing (prediction). The AUC values produced from the 10 -fold cross-validation were then averaged to indicate the performance of the MaxEnt model. Additionally, we tested the relative importance of the environmental variables as predictors, through a heuristic jackknife procedure implemented in MaxEnt (Phillips et al., 2006).

\section{The dynamical model}

The dynamical model used was an agent-based model of snail population dynamics and parasite development and transmission. The model was parameterised using data from experimental and field studies on the effects of water temperature on $B$. pfeifferi reproduction, development, and mortality; and on $S$. mansoni transmission, development and mortality. The main output of the model is referred to as infection risk, and is a measure of the number and relative infectiousness of cercariae in the model. Eight model scenarios were simulated, consisting of four temperature variations combined with two snail mortality rate variations (high and low). Four temperature variations were simulated as the relationship between air and water temperature varies between different types of water body, and at different water depths (McCreesh and Booth, 2013). The temperature variations were: i) water temperatures equal to air temperature, ii) water temperatures $2{ }^{\circ} \mathrm{C}$ higher than air temperatures, iii) water temperatures $2^{\circ} \mathrm{C}$ lower than air temperatures, and iv) daily maximum water temperatures $2^{\circ} \mathrm{C}$ lower than daily maximum air temperatures and daily minimum water temperatures $2^{\circ} \mathrm{C}$ higher than daily minimum air temperatures. Finally, the mean risk across model scenarios was calculated. Full details of the dynamical model are given in (McCreesh and Booth, 2014a) and McCreesh et al. (2015).

\section{Combined models}

The dynamical model and the snail habitat suitability models were combined using two different approaches for comparison: i) the dynamical model output was weighted by the continuous output from the snail models (by multiplication); and ii) by masking the dynamical model output map by the thresholded snail habitat suitability map, excluding areas that according to the snail habitat suitability model was not suitable $B$. pfeifferi.

\section{Baseline model evaluation and validation}

All baseline models were compared to empirical data on intestinal schistosomiasis prevalence in the human population. These data were extracted from open-access Global Neglected Tropical Disease (GNTD) database (Hurlimann et al., 2011), an open access database containing historical and contemporary survey data on schistosomiasis (and other neglected tropical diseases), and the data have been widely used in statistical models of disease prevalence (e.g., Karagiannis-Voules et al., 2015; Schur et al., 2013). The models were compared with all empirical data that were extracted for the study area, and with a subset of data selected data, which excluded the data which were considered to be least suitable for comparison purposes (data not exclusively from children, collected before 2003, or fewer than 10 observations). The per- formance of the combined and single- models (baseline, current conditions) was then evaluated by calculating the area under the receiver operating characteristic curve (AUC) for the ability of the model to predict observed $S$. mansoni prevalence in humans of above $0,10,20$ and $50 \%$, and by Spearman's rank correlation coefficient. Full details of the empirical data used are given in McCreesh et al. (2015).

\section{Climate projections and future risk scenarios}

For future projections of temperature as input for the dynamical model and precipitation (used as predictor in the statistical snail model) results from the African branch of the Coordinated Regional Downscaling Experiment (CORDEX) were used to provide projected daily data for the eastern Africa study region. Only one Regional Climate Model (RCM) simulation from the CORDEX-Africa matrix was selected as an example for the study. The simulation has been performed at the Swedish Meteorological and Hydrological Institute (SMHI) with the Rossby Centre RCM - SMHI-RCA4 (Nikulin et al., 2012) under the moderate Representative Concentration Pathway (RCP) scenario, RCP4.5. The simulated temperature and precipitation have been bias corrected by the Distribution Based Scaling method (Yang et al., 2010) using the WATCH WFDEI gridded product (Weedon et al., 2014) for the 1981-2010 period as a reference quasi-observational dataset. The CORDEX-Africa experiment covers the whole African continent at about a $50 \mathrm{~km}\left(0.44^{\circ}\right)$ resolution and a smaller subdomain in eastern Africa was selected for the study and has size of 1470 (35 x 42) grid boxes. For precipitation, three bioclimatic averages of seasonal variation (annual average, precipitation seasonality (coefficient of variation) and precipitation of the driest quarter), were used as indirect measures of the availability of suitable temporary water bodies that Biomphalaria snails are known to inhabit.

Daily minimum and maximum $2 \mathrm{~m}$ air temperature data, from the climate projections, were used to drive the dynamical model, and the model was run between 2006-2065 for each of the $35 \times 42$ grid boxes covering the study area. For each future climate projection and standalone/combined risk model, the median predicted changes in risk (across the 8 model scenarios) were calculated to give a central estimate of the magnitude of changes that may occur. The differences in predicted future change between stand-alone and combined models were evaluated by visually inspection of the output maps and by comparing the percentage of area (pixels) that are predicted to experience increase, decrease or status quo over the next 50 years.

\section{Results}

\section{Single- and combined model outputs under current conditions (baseline)}

The current condition distribution of $B$. pfeifferi as modelled by MaxEnt, is shown in Figure 1. The model output can be interpreted as the relative suitability of a given pixel in the map to sustain snail populations under baseline conditions. Overall snail habitat model performance based on AUC was very good (0.911, standard deviation=0.028). The contributions to model training gain of each environmental predictor (Table 2), revealed that predictors related to human modification of the environment [human influence index (HII) and distance to dams], were among the top explanatory factors for $B$. pfeifferi current distribution in eastern Africa. Figure 2 shows the dynamical model output at baseline, averaged over the 10 year period and across the eight scenarios. The figure can be interpreted as an indication of the relative suitability of temperatures for Schistosoma mansoni 
transmission. Full results for the dynamical model are given in McCreesh et al. (2015). The results of combing the dynamical and snail habitat suitability models (weighted by multiplication and by masking) are shown in Figure 3.

\section{Comparison of single- and combined models with empirical data}

Comparison of model output infection risk at baseline (2006-2015) with empirical prevalence estimates $(0,10,20$ and $50 \%$ prevalence cutoff thresholds), showed that the combined model almost always performed slightly better than the dynamical model, as evaluated by AUC, and the weighted combined model performed marginally better than the masked combined model (Table 3 ). This picture was reinforced by the Spearman rank correlation test between modelled infection risk and empirical prevalence estimates, with the combined model (weighted) having a Spearman rank correlation coefficient of $0.41(\mathrm{P}<0.0001)$, compared to $0.14(\mathrm{P}<0.02)$ for the dynamical model alone (Table 3$)$.

\section{Predicted changes in risk}

Figure 4 illustrates the median predicted change in S. mansoni infection risk (across the 8 described scenarios), over the next 50 years under the moderate (RCP4.5) climate change scenario for the dynamical model alone and the combined (weighted) model, respectively. There was general agreement between models in predicting changes in risk, ranging from $61.9-70.5 \%$ of the total eastern Africa area predicted to experience a general increase in risk over the next 50 years. The highest proportional area with increased risk was predicted by the combined (masked) model. The dynamical model predicted the highest proportional area to experience up-to $20 \%$ increase in risk (36\%), com-

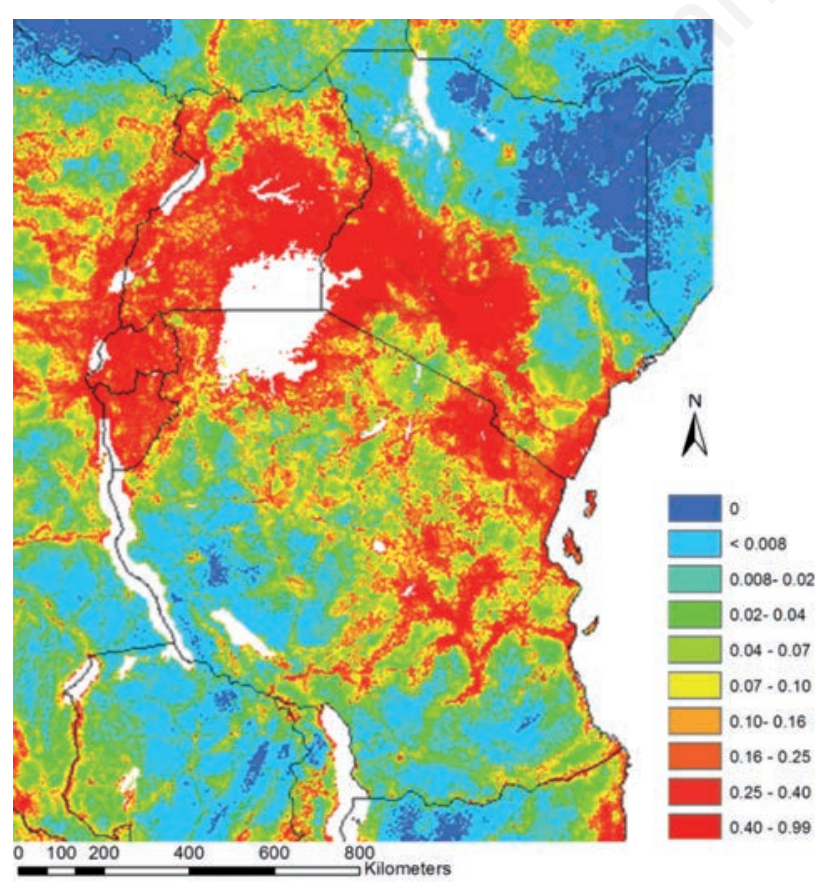

Figure 1. Habitat suitability map for Biomphalaria pfeifferi in eastern Africa (current conditions). Blue to red indicates increasing relative suitability. pared to $24 \%$ of the total area for the combined (weighted) model. Vice versa the models predicted a general decrease in risk in $30-37 \%$ of the study area. The biggest difference between the two maps in Figure 4 is the higher predicted increase in infection risk in central and northern Kenya by the combined model relative to the stand-alone dynamical model.

\section{Discussion}

Climate change will inevitably have an impact on schistosomiasis control and elimination programme outcomes, and thus there is a

Table 2. Estimates of relative contributions of the environmental variables to the snail habitat suitability model.

\begin{tabular}{lc} 
Variable & Contribution (\%) \\
HII & 48.3 \\
Distance to dams & 19.7 \\
\hline Distance to surface water bodies & 12 \\
Precipitation of driest quarter & 7.2 \\
\hline NDVI (rainy season) & 6 \\
Annual precipitation & 2.6 \\
\hline Land cover & 2.5 \\
Precipitation seasonality (coefficient of variation) & 1.3 \\
\hline Soil pH (topsoil) & 0.5
\end{tabular}

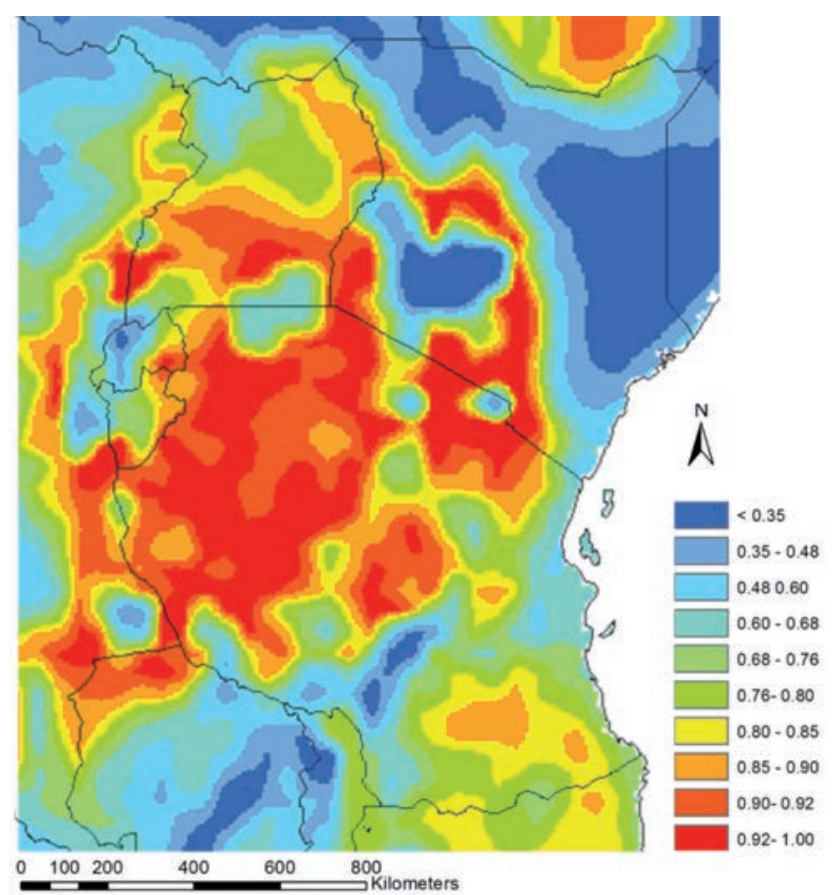

Figure 2. Baseline risk map from the dynamical model. Background colour shows model output infection risk, averaged across scenarios, and translated into proportion of maximum risk. 

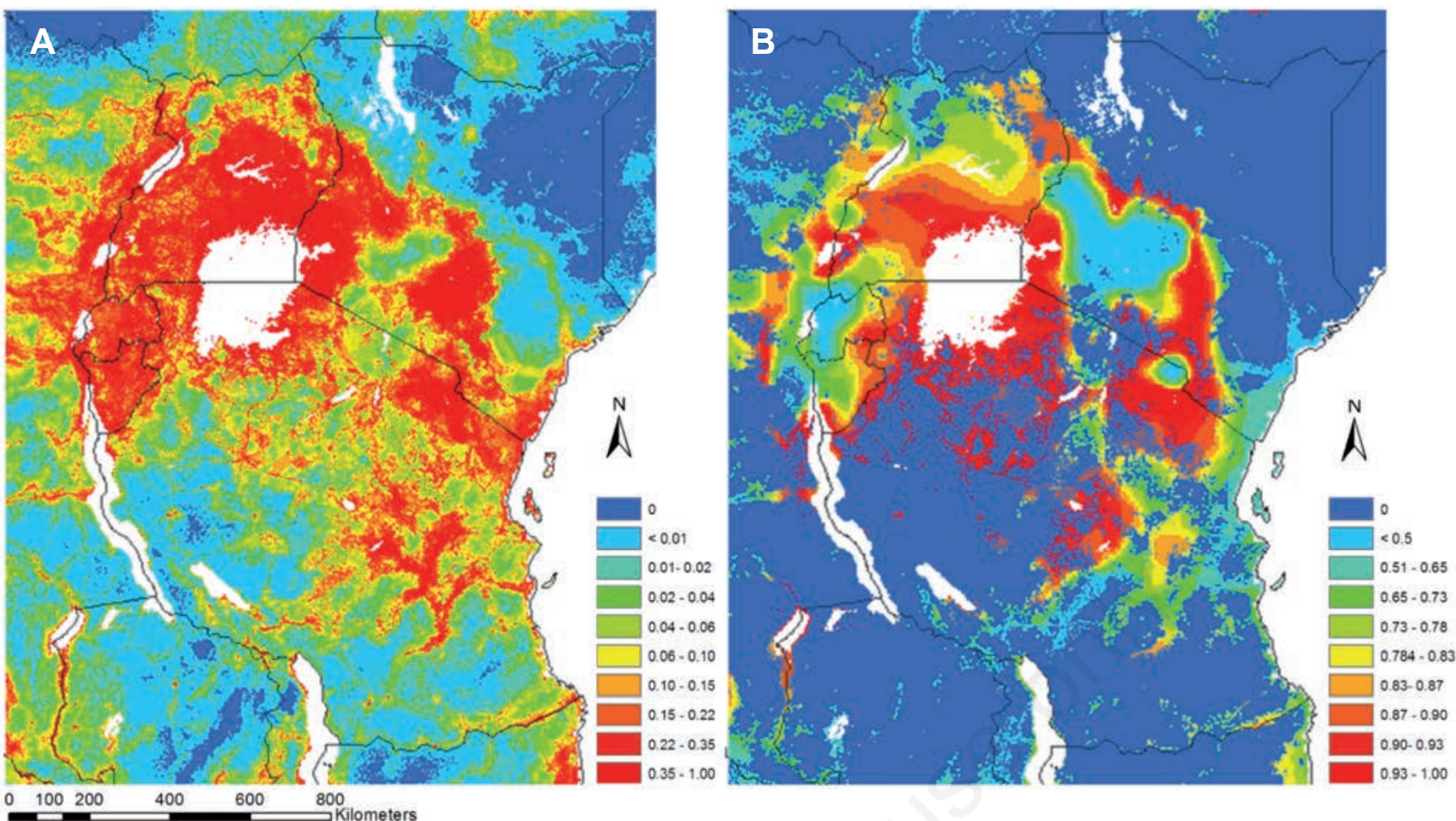

Figure 3. Combined models, current conditions. A) Output of combined model, where the dynamical model output is weighted by the snail habitat suitability model output; and B) output of models combined by masking the dynamical model with threshold (presenceabsence) snail habitat suitability model layer.
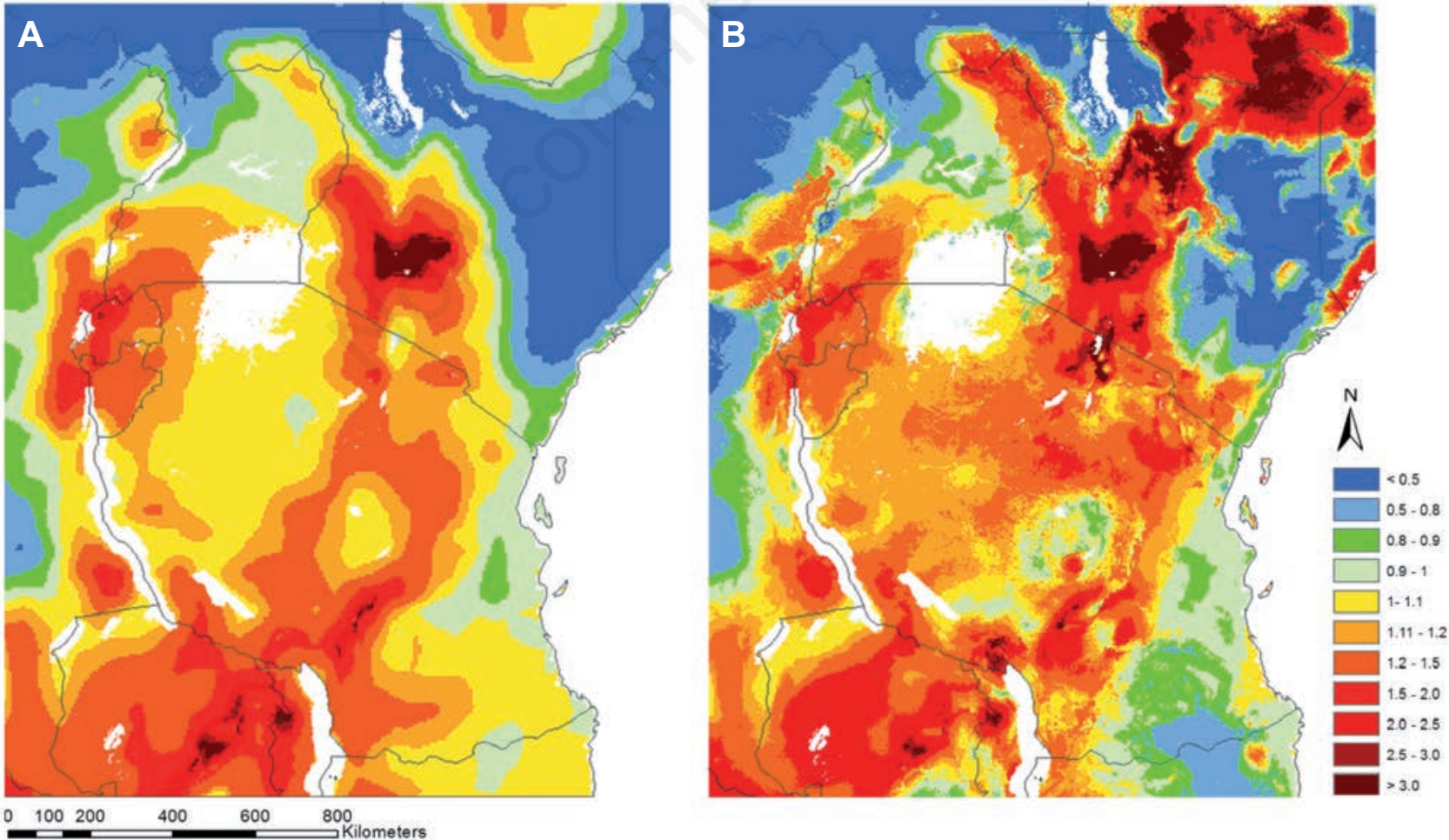

Figure 4. Predicted changes in risk. A) Dynamical model only; B) combined snail habitat statistical model and dynamical model (weighted). Results are for 2056-2065 relative to 2006-2015 (baseline), and median is calculated across eight model scenarios for each map. Cells with value $<1$ or $>1$ indicate future decrease or increase in infection risk, respectively. 
pressing need to improve model-based predictions about climate change impacts on the full parasite-snail system. Here, using independent, empirical schistosomiasis survey data to validate our models, we demonstrate that a combined-model approach is better able to capture the current (baseline) distribution of schistosomiasis than a dynamical approach (Table 3). The statistical model added information about the geographical distribution and habitat suitability for $B$. pfeifferi, which improved baseline predictions considerably. At the same time, the dynamical model allows the complex, non-linear relationship between temperature and schistosomiasis risk to be accurately captured, potentially greatly increasing the accuracy of future predictions.

Overall, the combined model predicted that more areas in eastern Africa are likely to experience an increase in risk (63\% of total area) than a decrease or status quo (37\% of total area). This is very similar to the predictions made by the original, dynamical model by McCreesh et al. (2015). On the other hand, the combined model estimated that a somewhat lower proportion of study area would experience an increase in of up-to $20 \%$ in risk (24 vs 36\%). The main reason for this difference is that some areas where the dynamical model predicts increased risk (particularly in southern and central parts of Tanzania), are considered by the statistical model to have very low suitability for snail existence. In areas that are predicted to experience a relative decrease in risk, decreases are due mainly to projected temperature regimes becoming increasingly unsuitable (i.e. too hot) to sustain snail populations.

It should however be noted that only one set of climate projections was used in this study, and caution is thus warranted with regards to making strong conclusions about the future distribution of schistosomiasis based on these projections. Repeating the analysis using multiple climate projections from difference sources would allow us to develop estimates of the level of uncertainty in our predictions, and highlight areas where current knowledge does not allow accurate predictions to be made. The main purpose of this study however, was to explore the potential benefits of combining a spatially-stratified empirical-statistical model of snail suitability with a dynamical model of $S$. mansoni infection in snails that used temperature as the only explanatory factor of spatial variation, and in terms of fitting the model output to existing prevalence data, the benefits are clear.

Another limitation to keep in mind when interpreting the results is the absence of the human element, which is central to the actual distribution of infection within and between populations. Incorporating the complex milieu of potentially confounding and modifying epidemiological, social, economic and demographic factors that add to the variation in the distribution and intensity of schistosomiasis, is perhaps one of the biggest challenges in modelling future transmission of schistosomiasis, and vector-borne diseases in general (Parham et al., 2015a).

Nevertheless, our results are consistent with earlier studies. A purely empirical-statistical snail model for the entire African continent (Stensgaard et al., 2013) predicted a general decrease of suitable habitat for $B$. pfeifferi, with a reduction in the total suitable are of up to $43 \%$. However, this was mainly due to conditions becoming unsuitable in many places in western Africa. In line with the findings of the present study, $B$. pfeifferi was predicted to expand its current distribution in areas of eastern and southern Africa. Our findings are also in line with the (to-date) only published empirical study of schistosomiasis and climate changes, which suggested that schistosome transmission potential is increasing as a result of warming in high altitude areas in Uganda (John et al., 2008). More generally, our results underscore the importance of combining knowledge of the biology and ecology of both parasites and intermediate host snails. Suitable snail habitats are a prerequisite for transmission, and it is essential to take the distribution of the intermediate host snail explicitly into account. However, the impact of environmental/climatic factors on different species intermediate host snails is diverse and specific to individual snail-parasite combination. This specificity requires tailored parameters for individual snail-parasite systems to more accurately project the impact of climatic changes on transmission, but such data are often unavailable (McCreesh and Booth, 2013). In the present study for instance, all models were parameterised to $B$. pfeifferi only due to lack of empirical data on other snail species. $B$. pfeifferi is the most widespread $S$. mansoni intermediate host in the region, but some of the prevalence data will come from sites with other snails, limiting model performance. Effects of temperature on infection risk can vary greatly depending on the snail species (McCreesh and Booth, 2014b), and while the range of $B$. pfeiffer $i$ is expected to decrease, the range of $B$. sudanica (another host species) is predicted to increase under global warming scenarios (Stensgaard et al., 2013).

Most importantly perhaps, this study (and others), suggest that nonclimatic factors - in particular anthropogenically altered habitat, such as dam developments - potentially play a more important role than climatic factors in determining the current distribution of the intermedi-

Table 3. Comparison of model output infection risk at baseline (2006-2015) with empirical prevalence thresholds (mean across 8 temperature scenarios) for the dynamical (agent-based) model, the statistical snail habitat suitability model, and the combined models.

\begin{tabular}{|c|c|c|c|c|c|c|c|c|}
\hline \multirow{2}{*}{ AUC } & \multicolumn{4}{|c|}{ All data } & \multicolumn{4}{|c|}{ Selected data } \\
\hline & $\begin{array}{l}\text { Dynamic } \\
\text { model }\end{array}$ & $\begin{array}{c}\text { Statistical } \\
\text { model }\end{array}$ & $\begin{array}{l}\text { Combined } \\
\text { (weighted) }\end{array}$ & $\begin{array}{l}\text { Combined } \\
\text { (masked) }\end{array}$ & $\begin{array}{c}\text { Dynamic } \\
\text { model }\end{array}$ & $\begin{array}{c}\text { Statistical } \\
\text { model }\end{array}$ & Combined & $\begin{array}{l}\text { Combined } \\
\text { (masked) }\end{array}$ \\
\hline $0 \%$ & $\begin{array}{c}0.59 \\
(0.51-0.66)\end{array}$ & $\begin{array}{c}0.69 \\
(0.62-0.77)\end{array}$ & $\begin{array}{c}0.68 \\
(0.61-0.76)\end{array}$ & $\begin{array}{c}0.64 \\
(0.56-0.71)\end{array}$ & $\begin{array}{c}0.57 \\
0.45-0.69)\end{array}$ & $\begin{array}{c}0.72 \\
(0.61-0.83)\end{array}$ & $\begin{array}{c}0.71 \\
(0.60-0.82)\end{array}$ & $\begin{array}{c}0.69 \\
(0.58-0.80)\end{array}$ \\
\hline $10 \%$ & $\begin{array}{c}0.59 \\
(0.52-0.66)\end{array}$ & $\begin{array}{c}0.72 \\
(0.66-0.79)\end{array}$ & $\begin{array}{c}0.73 \\
(0.67-0.80)\end{array}$ & $\begin{array}{c}0.69 \\
(0.63-0.76)\end{array}$ & $\begin{array}{c}0.63 \\
0.48-0.79)\end{array}$ & $\begin{array}{c}0.81 \\
(0.70-0.93)\end{array}$ & $\begin{array}{c}0.78 \\
(0.66-0.91)\end{array}$ & $\begin{array}{c}0.76 \\
(0.64-0.87)\end{array}$ \\
\hline $20 \%$ & $\begin{array}{c}0.60 \\
(0.51-0.68)\end{array}$ & $\begin{array}{c}0.69 \\
(0.61-0.76)\end{array}$ & $\begin{array}{c}0.71 \\
(0.63-0.79)\end{array}$ & $\begin{array}{c}0.69 \\
(0.61-0.77)\end{array}$ & $\begin{array}{c}0.75 \\
(0.56-0.94)\end{array}$ & $\begin{array}{c}0.83 \\
(0.70-0.95)\end{array}$ & $\begin{array}{c}0.82 \\
(0.70-0.94)\end{array}$ & $\begin{array}{c}0.79 \\
(0.65-0.93)\end{array}$ \\
\hline $50 \%$ & $\begin{array}{c}0.55 \\
(0.42-0.69)\end{array}$ & $\begin{array}{c}0.73 \\
(0.61-0.84)\end{array}$ & $\begin{array}{c}0.73 \\
(0.62-0.84)\end{array}$ & $\begin{array}{c}0.73 \\
(0.62-0.84)\end{array}$ & $\begin{array}{c}0.85 \\
(0.67-1.00)\end{array}$ & $\begin{array}{c}0.89 \\
(0.73-1.00)\end{array}$ & $\begin{array}{c}0.91 \\
(0.78-1.00)\end{array}$ & $\begin{array}{c}0.90 \\
(0.78-1.00)\end{array}$ \\
\hline $\begin{array}{l}\text { Spearman's } \\
\text { correlation }\end{array}$ & $\begin{array}{c}0.14 \\
(0.02)\end{array}$ & $\begin{array}{c}0.42 \\
(<0.0001)\end{array}$ & $\begin{array}{c}0.41 \\
(<0.0001)\end{array}$ & $\begin{array}{c}0.34 \\
(<0.0001)\end{array}$ & $\begin{array}{l}-0.04 \\
(0.7)\end{array}$ & $\begin{array}{c}0.48 \\
(<0.0001)\end{array}$ & $\begin{array}{c}0.45 \\
(<0.0001)\end{array}$ & $\begin{array}{c}0.43 \\
(<0.0001)\end{array}$ \\
\hline
\end{tabular}

coefficient

(P value)

AUC, area under the curve. 
ate snail host at regional scales. This means that we face an enormous challenge, as reliable future projections for changes in, for example, land use and land cover are not available. Currently, we have little choice but to treat these variables as static, and adopt a no changeassumption, that is not very realistic, although it is better than excluding them altogether (Stanton et al., 2012). However, we are not alone facing this challenge. Conservation scientists, to give one example, are also exploring new avenues (de Chazal and Rounsevell, 2009; Riordan and Rundel, 2014), and a combined effort here could perhaps lead to new ways to address this challenge.

\section{Conclusions}

In conclusion, we suggest that ways to combine, hybridise or couple statistical-empirical distribution modelling with process-based models of snail lifecycles and parasite development, underpinned by a solid knowledge of snail ecology, be further explored. One approach is not intrinsically superior to the other (Dormann et al., 2012), and by combining them, the knowledge and insight that can be gained from available data, experimental and/or empirical, is maximised.

This approach, however, can only be fully exploited, if the current paucity of biological data needed to parameterise the different models to single species' responses to changes in abiotic conditions is addressed (McCreesh et al., 2013). Combining a full set of such species-specific details with knowledge of the complex ecological, evolutionary and societal aspects that determine the variation in the distribution and intensity of disease may be the most promising way forward in the challenging field of predicting the impacts of climate change on schistosomiasis, and vector-borne diseases in general.

\section{References}

Appleton CC, 1978. Review of literature on abiotic factors influencing the distribution and life cycle of bilharzia intermediate host snails. Malacol Rev 1978:1-25.

de Chazal J, Rounsevell MDA, 2009. Land-use and climate change within assessments of biodiversity change: a review. Global Environ Chang 19:306-15.

Dormann CF, Schymanski SJ, Cabral J, Chuine I, Graham C, Hartig F, Kearney M, Morin X, Romermann C, Schroder B, Singer A, 2012. Correlation and process in species distribution models: bridging a dichotomy. J Biogeogr 39:2119-31.

Elith J, Graham CH, Anderson RP, Dudik M, Ferrier S, Guisan A, Hijmans RJ, Huettmann F, Leathwick JR, Lehmann A, Li J, Lohmann LG, Loiselle BA, Manion G, Moritz C, Nakamura M, Nakazawa Y, Overton JM, Peterson AT, Phillips SJ, Richardson K, Scachetti-Pereira R, Schapire RE, Soberon J, Williams S, Wisz MS, Zimmermann NE, 2006. Novel methods improve prediction of species' distributions from occurrence data. Ecography 29:129-51.

Foster R, 1964. Effect of temperature on development of Schistosoma Mansoni Sambon 1907 in intermediate host. J Trop Med Hyg 67:289-92.

Hirzel AH, Le Lay G, Helfer V, Randin C, Guisan A, 2006. Evaluating the ability of habitat suitability models to predict species presences. Ecol Model 199:142-52.

Hurlimann E, Schur N, Boutsika K, Stensgaard AS, de Himpsl ML, Ziegelbauer K, Laizer N, Camenzind L, Di Pasquale A, Ekpo UF,
Simoonga C, Mushinge G, Saarnak CFL, Utzinger J, Kristensen TK, Vounatsou P, 2011. Toward an open-access global database for mapping, control, and surveillance of neglected tropical diseases. PLoS Neglect Trop D 5:e1404.

IPCC, 2013. Climate change 2013: the physical science basis. Intergovernmental Panel on Climate Change, Bern, Switzerland. Available from: www.climatechange2013.org/images/report/ WG1AR5_ALL_FINAL.pdf

John R, Ezekiel M, Philbert C, Andrew A, 2008. Schistosomiasis transmission at high altitude crater lakes in Western Uganda. BMC Infect Dis 8:110.

Karagiannis-Voules DA, Biedermann P, Ekpo UF, Garba A, Langer E, Mathieu E, Midzi N, Mwinzi P, Polderman AM, Raso G, Sacko M, Talla I, Tchuente LAT, Toure S, Winkler MS, Utzinger J, Vounatsou $P, 2015$. Spatial and temporal distribution of soil-transmitted helminth infection in sub-Saharan Africa: a systematic review and geostatistical meta-analysis. Lancet Infect Dis 15:74-84.

Mangal TD, Paterson S, Fenton A, 2008. Predicting the impact of longterm temperature changes on the epidemiology and control of schistosomiasis: a mechanistic model. PLoS One 3:e1438.

Martens WJM, Jetten TH, Focks DA, 1997. Sensitivity of malaria, schistosomiasis and dengue to global warming. Climatic Change 35:14556 .

Martens WJM, Jetten TH, Rotmans J, Niessen LW, 1995. Climate change and vector-borne diseases: a global modelling perspective. Global Environ Chang 5:195-209.

McCreesh N, Booth M, 2013. Challenges in predicting the effects of climate change on Schistosoma mansoni and Schistosoma haematobium transmission potential. Trends Parasitol 29:548-55.

McCreesh N, Booth M, 2014a. The effect of increasing water temperatures on Schistosoma mansoni transmission and Biomphalaria pfeifferi population dynamics: an agent-based modelling study. PLoS One 9:e101462.

McCreesh N, Booth M, 2014b. The effect of simulating different intermediate host snail species on the link between water temperature and schistosomiasis risk. PLoS One 9:e87892.

McCreesh N, Nikulin G, Booth M, 2015. Predicting the effects of climate change on Schistosoma mansoni transmission in eastern Africa. Parasite Vector 8:4.

Mwase ET, Stensgaard AS, Msakashalo-Senkwe M, Mubila L, Mwansa J, Songolo P, Shawa ST, Simonsen PE, 2014. Mapping the geographical distribution of lymphatic filariasis in Zambia. PLoS Neglect Trop D 8:e2714.

Nikulin G, Jones C, Giorgi F, Asrar G, Buchner M, Cerezo-Mota R, Christensen OB, Deque M, Fernandez J, Hansler A, van Meijgaard E, Samuelsson P, Sylla MB, Sushama L, 2012. Precipitation climatology in an ensemble of CORDEX-Africa regional climate simulations. J Climate 25:6057-78.

Parham PE, Waldock J, Christophides GK, Hemming D, Agusto F, Evans KJ, Fefferman N, Gaff H, Gumel A, LaDeau S, Lenhart S, Mickens RE, Naumova EN, Ostfeld RS, Ready PD, Thomas MB, VelascoHernandez J, Michael E, 2015a. Climate, environmental and socioeconomic change: weighing up the balance in vector-borne disease transmission. Philos T Roy Soc B 370:20130551.

Parham PE, Waldock J, Christophides GK, Michael E, 2015b. Climate change and vector-borne diseases of humans. Preface. Philos T Roy Soc B 370:20140377.

Pearson RG, Dawson TP, 2003. Predicting the impacts of climate change on the distribution of species: are bioclimate envelope models useful? Global Ecol Biogeogr 12:361-71.

Pedersen UB, Midzi N, Mduluza T, Soko W, Stensgaard AS, Vennervald 
BJ, Mukaratirwa S, Kristensen TK, 2014. Modelling spatial distribution of snails transmitting parasitic worms with importance to human and animal health and analysis of distributional changes in relation to climate. Geospat Health 8:335-43.

Pfluger W, 1980. Experimental epidemiology of Schistosomiasis. 1. The prepatent period and cercarial production of Schistosoma mansoni in Biomphalaria snails at various constant temperatures. Z Parasitenkd 63:159-69.

Phillips SJ, Anderson RP, Schapire RE, 2006. Maximum entropy modeling of species geographic distributions. Ecol Model 190:231-59.

Riordan EC, Rundel PW, 2014. Land use compounds habitat losses under projected climate change in a threatened California ecosystem. PLoS One 9:e86487.

Schur N, Hurlimann E, Stensgaard AS, Chimfwembe K, Mushinge G, Simoonga C, Kabatereine NB, Kristensen TK, Utzinger J, Vounatsou P, 2013. Spatially explicit Schistosoma infection risk in eastern Africa using Bayesian geostatistical modelling. Acta Trop 128:365-77.

Signorini M, Cassini R, Drigo M, Frangipane di Regalbono A, Pietrobelli M, Montarsi F, Stensgaard AS, 2014. Ecological niche model of Phlebotomus perniciosus, the main vector of canine leishmaniasis in north-eastern Italy. Geospat Health 9:193-201.

Simoonga C, Utzinger J, Brooker S, Vounatsou P, Appleton CC, Stensgaard AS, Olsen A, Kristensen TK, 2009. Remote sensing, geographical information system and spatial analysis for schistosomiasis epidemiology and ecology in Africa. Parasitology 136:1683-93.

Stanton JC, Pearson RG, Horning N, Ersts P, Akcakaya HR, 2012. Combining static and dynamic variables in species distribution models under climate change. Methods Ecol Evol 3:349-57.
Stensgaard A, Jorgensen A, Kabatereine NB, Malone JB, Kristensen TK, 2005. Modeling the distribution of Schistosoma mansoni and host snails in Uganda using satellite sensor data and Geographical Information Systems. Parassitologia 47:115-25.

Stensgaard AS, Jorgensen A, Kabatereine NB, Rahbek C, Kristensen TK, 2006. Modeling freshwater snail habitat suitability and areas of potential snail-borne disease transmission in Uganda. Geospat Health 1:93-104.

Stensgaard AS, Utzinger J, Vounatsou P, Hurlimann E, Schur N, Saarnak CFL, Simoonga C, Mubita P, Kabatereine NB, Tchuente LAT, Rahbek C, Kristensen TK, 2013. Large-scale determinants of intestinal schistosomiasis and intermediate host snail distribution across Africa: does climate matter? Acta Trop 128:378-90.

Utzinger J, Brattig NW, Kristensen TK, 2013. Schistosomiasis research in Africa: how the CONTRAST alliance made it happen. Acta Trop 128:182-95.

Weedon GPG, Balsamo N, Bellouin S, Gomes M, Best J, Viterbo P, 2014. The WFDEI meteorological forcing data set: WATCH forcing data methodology applied to ERA-Interim reanalysis data. Water Resour Res 50:7505-14.

Yang W, Andréasson J, Graham LP, Olsson J, Rosberg J, Wetterhall F, 2010. Distribution-based scaling to improve usability of regional climate model projections for hydrological climate change impacts studies. Hydrol Res 41:211-29.

Zhou XN, Yang GJ, Yang K, Wang XH, Hong QB, Sun LP, Malone JB, Kristensen TK, Bergquist NR, Utzinger J, 2008. Potential impact of climate change on Schistosomiasis transmission in China. Am J Trop Med Hyg 78:188-94. 